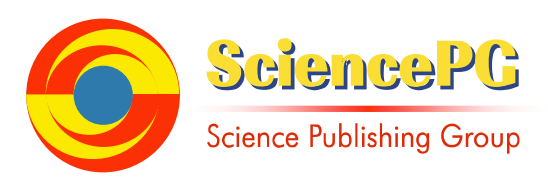

\title{
Endoscopic Findings in Egyptian Patients with Oesophageal Dysphagia at Different Age Groups
}

\author{
Marwa Ahmed Saad Gouda ${ }^{1, *}$, Ahmed Ismail Al-lakani², Magdy Mohammed Bedewy ${ }^{3}$ \\ ${ }^{1}$ Internal Medicine Department, Geriatric Unit, Faculty of Medicine, Alexandria University, Alexandria, Egypt \\ ${ }^{2}$ Internal Medicine, Internal Medicine Department, Gastroenterology Unit; Faculty of Medicine, Alexandria University, Alexandria, Egypt \\ ${ }^{3}$ Histo-Pathology, Pathology Department, Military Academy Hospital, Alexandria, Egypt
}

\section{Email address:}

drmarwasaad74@gmail.com (M. A. S. Gouda),D.ahmedellakany@yahoo.com (Ahmed I. Al-Lakani),

Mgbedewy@gmail.com (M. M. Bedewy)

\section{To cite this article:}

Marwa Ahmed Saad Gouda, Ahmed Ismail Al-lakani, Magdy Mohammed Bedewy. Endoscopic Findings in Egyptian Patients with Oesophageal Dysphagia at Different Age Groups. American Journal of Internal Medicine. Vol. 3, No. 6, 2015, pp. 224-230.

doi: 10.11648 j.ajim.20150306.12

\begin{abstract}
Dysphagia is the medical term for the symptom of difficulty in swallowing. Dysphagia can occur in all age groups, and its prevalence increases with aging. Diagnosis of dysphagia is important due to associated morbidity and mortality, so it warrants early evaluation. The current study aimed to determine the frequency of common endoscopic findings in Egyptian patients presenting with esophageal dysphagia. This cross-sectional, descriptive study was carried out in the department of Gastroenterology, faculty of medicine, Alexandria University in the period from January 2012 -December 2014.127 patients with dysphagia were included in the study and were subjected to endoscopy. A total of 127 patients; 73 females (57.5\%), and 54 males $(42.5 \%)$ presenting with dysphagia were studied, the mean age was $49.56 \pm 16.41$ years. gastro-esophageal reflux (GERD)/reflux esophagitis was the most common findings noted in 25(19.7\%) patients, followed by esophageal stricture noted in 22 patients (17.3\%), esophageal mass in 21 patients (16.5\%), normal endoscopic findings in 20 patients $(15.7 \%)$, achalasia of the esophagus in 12 patients $(9.4 \%)$, eosinophilic esophagitis in $6(4.7 \%)$ patients, esophageal web/rings in $5(3.9 \%)$ patients, diffuse esophageal spasm in 4 patients (3.1\%), foreign body impaction in 2 patients $(1.6 \%)$, and hiatal hernia in 2 patients (1.6). $8(6.3 \%)$ patients had findings other than the ones mentioned above. We concluded that GERD/reflux esophagitis, and esophageal strictures are the commonest causes of dysphagia in our population. Also malignant esophageal mass is the main cause of dysphagia in elderly population, both warrants early diagnosis and management.
\end{abstract}

Keywords: Dysphagia, Endoscopy, Malignancy, Reflux Esophagitis, Esophageal Stricture

\section{Introduction}

Dysphagia is the medical term for the symptom of difficulty in swallowing [1]. The word is de-rived from the Greek dysmeaning disordered, and the root phag- meaning "eat". It suggests difficulty in the passage of solids or liquids from the mouth to the stomach, a lack of pharyngeal sensation, or various other inadequacies of the swallowing mechanism [2]. Swallowing disorders can occur in all age groups, resulting from congenital abnormalities, structural damage, and/or medical conditions [3]. A population-based study found the overall prevalence of dysphagia to be $13.5 \%$ [4]. The prevalence increases to $22.3 \%$ in individuals 55 years and older [5]. The prevalence ranges between $29 \%$ and $64 \%$ in patients who have had strokes [6,7], and more than $40 \%$ in patients in institutionalized settings[8].

Swallowing is a complex neuromuscular activity consisting of three phases, an oral, pharyngeal and esophageal phase, using both skeletal muscle (tongue) and smooth muscles of the pharynx and esophagus. Normal aging is associated with cerebral atrophy, deterioration in nerve function, and decline in muscle mass, which may adversely affect swallowing function [9].

Dysphagia is classified into three major types: 1) Oropharyngeal dysphagia, 2) Esophageal dysphagia, and 3) Functional dysphagia [10]. Esophageal dysphagia is almost always caused by disease in or adjacent to the esophagus but occasionally the lesion is in the pharynx or stomach. It may result from structural or neuromuscular disorders of the esophagus [11]. Common causes of esophageal dysphagia include: 
1) Esophageal strictures: Peptic strictures account for $70-80 \%$ of all cases of esophageal stricture, due to gastro-esophageal reflux (GERD) [12]. These patients are usually older and have had GERD for a long time. Other non-acid related causes of peptic strictures include infectious esophagitis, ingestion of chemical irritant, pill irritation, and radiation.

2) Esophageal cancer, usually affects the elderly. Esophageal cancers can be either squamous cell carcinoma or adenocarcinoma. Adenocarcinoma is the most prevalent type in the US [13], and is noted in patients with chronic GERD who have developed Barrett's esophagus [14]. Squamous cell carcinoma is more prevalent in Asia and is associated with tobacco smoking and alcohol use [13].

3) Achalasia of the esophagus is an idiopathic motility disorder characterized by failure of lower esophageal sphincter (LES) relaxation, as well as loss of peristalsis in the distal esophagus in the absence of other explanations like cancer or fibrosis [15]. Persons with achalasia lack non-adrenergic, non-cholinergic, inhibitory ganglion cells, causing an imbalance in excitatory and inhibitory neurotransmission. The result is a hypertensive non-relaxed esophageal sphincter. Other studies suggest autoimmune, hereditary, neurodegenerative, genetic and infective contributions [16].

4) Esophageal rings (Schatzki rings) are usually mucosal rings rather than muscular rings, and are located near the gastro-esophageal junction at the squamo-columnar junction [17]. The pathogenesis is not clear, and patients typically present with intermittent non-progressive dysphagia for solids.

5) Esophageal webs; usually squamous mucosal protrusion into the esophageal lumen, especially anterior cervical esophagus behind the cricoid area. An important association of esophageal webs is to the Plummer-Vinson syndrome in iron deficiency anemia.

6) Diffuse esophageal spasm: It is a condition in which uncoordinated contractions of the esophagus occur. Its causes are not well under-stood. It is thought, however, that many cases are caused by uncontrolled brain signals running to nerve endings. Research is ongoing to determine the underlying causes to improve diagnostic capabilities and therapeutic regimens in the future [18].

7) Eosinophilic esophagitis (EoE) is an inflammatory condition of the esophagus that involves eosinophils. The condition is not well understood, but food allergy may play a significant role [19].

Diagnosis of dysphagia is important due to associated morbidity and mortality [20]. Upper gastro-intestinal endoscopy is an effective tool for the diagnostic evaluation and management of patients with dysphagia, as it allows direct visualization of the lesion within the esophagus [20]. Upper GI Endoscopy is considered a safe procedure with a complication risk of approximately1 per 1000 procedures which include bleeding, infection, perforation, cardio-pulmonary problems [21].

The current study aimed to determine the frequency of common endoscopic findings in Egyptian patients presenting with esophageal dysphagia.

\section{Materials and Methods}

This cross-sectional study was carried out in the department of Gastroenterology, faculty of Medicine, Alexandria University from January 2012 to December 2014. 127 Patients were included in the present study 18 years and older, of both genders who attended gastroenterology and geriatric outpatient clinics. All patients were complaining of dysphagia with duration varied from one week up to 24 weeks. The proposal of the study was accepted by the ethical committee of Alexandria University. The Procedure, purpose and benefits of the study were explained to the patients and a fully informed, written consent was obtained.

Patients were admitted to the Gastroenterology unit of faculty of medicine, Alexandria University for preparation for Upper GI endoscopy after taking a detailed history, performing a thorough physical examination and carrying out the necessary baseline investigations. Upper GI endoscopy was performed and findings were identified as esophageal stricture, normal findings, gastro-esophageal reflux disease (GERD)/reflux esophagitis, achalasia of the esophagus, Schatzki's ring, food impaction, suspected malignant esophageal mass. Biopsies were taken from suspected lesions, and sent for histo-pathological examination by an expert histopathologist to determine its nature either benign or malignant.

All data recorded was entered and analyzed in SPSS/version 20 software. Frequency and percentages were calculated for categorical variables like gender and common upper GI Endoscopic findings. Mean \pm SD were calculated for numerical variables like age and duration of dysphagia. Chi square test was used to find the significant difference. The level of significant was 0.05. Common upper GI Endoscopic findings were stratified among age, gender and duration of dysphagia to see the effect modifiers.

\section{Results}

The present study included 127 patients; 73 females (57.5\%), and 54 males (42.5\%). Their age ranged between $18-81$ years, with a mean of $49.56 \pm 16.41$ years. The patients were divided into three groups according to their age; patients below 30 years, those between $30-50$ years, and patients above 50 years. Majority of the patients, $66(51.9 \%)$ were in the age group above 50 years; 34 males $(63.0 \%)$, and 32 females $(43.8 \%)$,followed by 45 patients $(35.4 \%)$ in the age group 30-50 years; 36 females (49.3\%), and 9 males (16.7\%), and 16 patients $(12.6 \%)$ in the age group less than 30 years; 11 males $(20.4 \%)$, and 5 females $(6.8 \%)$. All patients had dysphagia with a duration ranged from 1-24 weeks. According to the duration of dysphagia, patients were classified into three groups, i.e., less than 12 weeks, from 12-24 weeks, and more 
than 24 weeks. Most of the patients 75 (59.1\%) were having dysphagia for more than 24 weeks, followed by 47 patients $(37 \%)$ in the $12-24$ weeks group and 5 patients $(3.9 \%)$ in the group having dysphagia for less than 12 weeks. Regarding the endoscopic findings, gastro-esophageal reflux (GERD)/reflux esophagitis was the most common findings noted in $25(19.7 \%$ ) patients, followed by esophageal stricture noted in 22 patients (17.3\%), esophageal mass in 21 patients $(16.5 \%)$, normal endoscopic findings in 20 patients $(15.7 \%)$, achalasia of the esophagus in 12 patients $(9.4 \%)$, other pathology in 8 patients (6.3\%) patients, eosinophilic esophagitis in $6(4.7 \%)$ patients, esophageal web/rings in $5(3.9 \%)$ patients, diffuse esophageal spasm in 4 patients ( $3.1 \%$ ), foreign body impaction in 2 patients $(1.6 \%)$, and hiatal hernia in 2 patients (1.6). (Table-1)

Table 1. Demographic data and endoscopic findings of the patients.

\begin{tabular}{|c|c|c|}
\hline & Number & Percent (\%) \\
\hline \multicolumn{3}{|l|}{ Gender } \\
\hline Male & 54 & 42.5 \\
\hline Female & 73 & 57.5 \\
\hline \multicolumn{3}{|l|}{ Age group } \\
\hline$<30$ & 16 & 12.6 \\
\hline $30-50$ & 45 & 35.4 \\
\hline $50+$ & 66 & 51.9 \\
\hline \multicolumn{3}{|l|}{ Duration group (weeks) } \\
\hline$<12$ & 5 & 3.9 \\
\hline $12-24$ & 47 & 37.0 \\
\hline $24+$ & 75 & 59.1 \\
\hline \multicolumn{3}{|l|}{ Endoscopic findings } \\
\hline GERD/ reflux esophagitis & 25 & 19.7 \\
\hline Esophageal stricture & 22 & 17.3 \\
\hline Esophageal mass & 21 & 16.5 \\
\hline Normal findings & 20 & 15.7 \\
\hline Achalasia & 12 & 9.4 \\
\hline Other findings & 8 & 6.3 \\
\hline Eosinophilic esophagitis & 6 & 4.7 \\
\hline Esophageal web/ring & 5 & 3.9 \\
\hline Diffuse esophageal spam & 4 & 3.1 \\
\hline Hiatal hernia & 2 & 1.6 \\
\hline Foreign body impaction & 2 & 1.6 \\
\hline
\end{tabular}

Biopsies from suspicious lesions were taken, and sent for histo- pathological examination, all patients with suspected esophageal mass 21 (40.4\%) were confirmed to be malignant, none of the cases had benign masses. Biopsies from 22 patients $(42.3 \%)$ with esophageal strictures revealed benign stricture in 17 patients $(77.3 \%)$, and malignant stricture in 5 patients $(22.7 \%)$. Barrett's esophagus was detected in two patients $(6.3 \%)$ with GERD. One suspected case (1.9\%) with achalasia found to be benign. Suspected cases of esinophilic esophagitis, confirmed by detection of more than 15 eosinophils / high power field (HPF) in esophageal biopsies. Also, biopsies from patients with normally appearing esophagus sent for histopathology which revealed mild degrees of non-specific inflammation in $9(45 \%)$ patients. Patients with other pathologies revealed; external compression of the esophagus by mediastinal masses in
$3(37.5 \%)$ patients, diverticula in another $3(37.5 \%)$ patients, and scleroderma in $2(25 \%)$ patients.

Gastro-esophageal reflux (GERD)/reflux esophagitis was commoner in females; 15 females were affected $(20.5 \%)$ versus 10 males $(18.5 \%)$, while achalasia is commoner in males; 9 males were affected $(16.7 \%)$ versus 3 females $(4.1 \%)$. Normal endoscopic findings were equal in both genders with 10females (13.7\%) and 10 males (18.5\%) affected. Other findings were commoner in females; other pathology was found in 6 females $(8.2 \%)$ versus 2 males(3.7\%), eosinophilic esophagitis in 4 females( $5.5 \%)$ versus 2 males(3.7\%), esophageal mass in 12 females( $16.4 \%$ ) versus 9 males $(16.7 \%)$, esophageal stricture in 12 females $(16.4 \%)$ versus 10 males(18.5\%), esophageal web/ring in 4 females $(5.5 \%)$ versus one male( $1.9 \%)$, esophageal spasm in 3 females $(4.1 \%)$ versus one male(1.9\%), hiatal hernia in only two females $(2.8 \%)$, and foreign body impaction in another 2 females $(2.7 \%)$. (Table-2)

Table 2. Endoscopic findings in relation to gender.

\begin{tabular}{|c|c|c|c|c|}
\hline \multirow{2}{*}{ Endoscopic findings } & & \multicolumn{2}{|l|}{ Gender } & \multirow{2}{*}{ Total } \\
\hline & & Male & Female & \\
\hline \multirow{2}{*}{ Achalasia } & No. & 9 & 3 & 12 \\
\hline & $\%$ & $16.7 \%$ & $4.1 \%$ & $9.4 \%$ \\
\hline \multirow{2}{*}{ Other findings } & No. & 2 & 6 & 8 \\
\hline & $\%$ & $3.7 \%$ & $8.2 \%$ & $6.3 \%$ \\
\hline \multirow{2}{*}{ Eosinophilic esophagitis } & No. & 2 & 4 & 6 \\
\hline & $\%$ & $3.7 \%$ & $5.5 \%$ & $4.7 \%$ \\
\hline \multirow{2}{*}{ Esophageal mass } & No. & 9 & 12 & 21 \\
\hline & $\%$ & $16.7 \%$ & $16.4 \%$ & $16.5 \%$ \\
\hline \multirow{2}{*}{ Esophageal stricture } & No. & 10 & 12 & 22 \\
\hline & $\%$ & $18.5 \%$ & $16.4 \%$ & $17.3 \%$ \\
\hline \multirow{2}{*}{ Esophageal web/ring } & No. & 1 & 4 & 5 \\
\hline & $\%$ & $1.9 \%$ & $5.5 \%$ & $3.9 \%$ \\
\hline \multirow{2}{*}{ Foreign body impaction } & No. & 0 & 2 & 2 \\
\hline & $\%$ & $0.0 \%$ & $2.7 \%$ & $1.6 \%$ \\
\hline \multirow{2}{*}{ GERD/reflux esophagitis } & No. & 10 & 15 & 25 \\
\hline & $\%$ & $18.5 \%$ & $20.5 \%$ & $19.7 \%$ \\
\hline \multirow{2}{*}{ Hiatal hernia } & No. & 0 & 2 & 2 \\
\hline & $\%$ & $0.0 \%$ & $2.8 \%$ & $2.8 \%$ \\
\hline \multirow{2}{*}{ Normal findings } & No. & 10 & 10 & 20 \\
\hline & $\%$ & $18.5 \%$ & $13.7 \%$ & $15.7 \%$ \\
\hline \multirow{2}{*}{ Diffuse esophageal spam } & No. & 1 & 3 & 4 \\
\hline & $\%$ & $1.9 \%$ & $4.1 \%$ & $3.1 \%$ \\
\hline \multirow{2}{*}{ Total } & No. & 54 & 73 & 127 \\
\hline & $\%$ & $100.0 \%$ & $100.0 \%$ & $100.0 \%$ \\
\hline \multicolumn{2}{|l|}{$\mathrm{X} 2$} & \multicolumn{2}{|l|}{13.197} & \\
\hline \multicolumn{2}{|l|}{$\mathrm{P}$} & \multicolumn{2}{|l|}{0.281} & \\
\hline
\end{tabular}

Apart from the normal upper GI endoscopy, some endoscopic findings were more common as the age of the patients increased indicating that the prevalence of these conditions increases with age. In the age group more than 50 years, the most common finding was esophageal mass found in 18 patients $(29.5 \%)$, all were proven to be malignant by histopathological examination, followed by GERD found in 17 patients $(25.7 \%)$, then malignant esophageal stricture in 9 patients $(13.6 \%)$, normal findings were found in 8 patients 
(12.1\%), other pathologies were less common; other pathology was found in 6 patients $(9.1 \%)$, esinophilic esophagitis in 2 patients, esophageal spasm in 2 patients (3\%), and foreign body impaction in another 2 patients $(3 \%)$, the least common findings were esophageal web/ring found in only one patient $(1.5 \%)$, and hiatal hernia in another one patient (1.5\%). No cases of achalasia were found in this age group.

In the age group from 30-50years, the most common finding was esophageal stricture found in 11 patients $(24.4 \%)$, all proved to be benign by histo-pathological examination, followed by normal findings found in 9 patients (20\%), 5 patients (11.1\%) were found to have GERD/reflux esophagitis, and achalasia in another 5 patients (11.1\%). Esinophilic esophagitis was found in 4 patients $(8.9 \%)$, and esophageal web/ring in another 4 patients $(8.9 \%)$. On contrary to the previous group, malignant esophageal mass was found in only 3 patients $(6.7 \%)$. The least common were esophageal spasm found in 2 patients $(4.4 \%)$, hiatal hernia in one patient $(2.2 \%)$, and combined pathology in another one patients $(2.2 \%)$. In the age group less than 30 years, the most common finding was achalasia of the esophagus found in 7 patients (43.8\%), followed by equal prevalence of both GERD and normal findings $(18.8 \%)$, then benign esophageal stricture in 2 patients $(12.5 \%)$, and the least common was other pathology found in only one patient $(6.3 \%)$.(Table 3 )

Table 3. Endoscopic findings in relation to Age group.

\begin{tabular}{|c|c|c|c|c|c|}
\hline \multirow[b]{2}{*}{ Endoscopic findings } & \multicolumn{5}{|c|}{ Total } \\
\hline & & $\begin{array}{l}<30 \\
\text { years }\end{array}$ & $\begin{array}{l}30-50 \\
\text { years }\end{array}$ & $50+$ years & Total \\
\hline \multirow{2}{*}{ Achalasia } & No. & 7 & 5 & 0 & 12 \\
\hline & $\%$ & $43.8 \%$ & $11.1 \%$ & $0.0 \%$ & $9.4 \%$ \\
\hline \multirow{2}{*}{ Other findings } & No. & 1 & 1 & 6 & 8 \\
\hline & $\%$ & $6.3 \%$ & $2.2 \%$ & $9.1 \%$ & $6.3 \%$ \\
\hline \multirow{2}{*}{$\begin{array}{l}\text { Eosinophilic } \\
\text { esophagitis }\end{array}$} & No. & 0 & 4 & 2 & 6 \\
\hline & $\%$ & $0.0 \%$ & $8.9 \%$ & $3 \%$ & $4.7 \%$ \\
\hline \multirow{2}{*}{ Esophageal mass } & No. & 0 & 3 & 18 & 21 \\
\hline & $\%$ & $.0 \%$ & $6.7 \%$ & $27.3 \%$ & $16.5 \%$ \\
\hline \multirow{2}{*}{ Esophageal stricture } & No. & 2 & 11 & 9 & 22 \\
\hline & $\%$ & $12.5 \%$ & $24.4 \%$ & $13.6 \%$ & $17.3 \%$ \\
\hline \multirow{2}{*}{ Esophageal web/ring } & No. & 0 & 4 & 1 & 5 \\
\hline & $\%$ & $0.0 \%$ & $8.9 \%$ & $1.5 \%$ & $3.9 \%$ \\
\hline \multirow{2}{*}{$\begin{array}{l}\text { Foreign body } \\
\text { impaction }\end{array}$} & No. & 0 & 0 & 2 & 2 \\
\hline & $\%$ & $0.0 \%$ & $0.0 \%$ & $3 \%$ & $1.6 \%$ \\
\hline \multirow{2}{*}{$\begin{array}{l}\text { GERD/reflux } \\
\text { esophagitis }\end{array}$} & No. & 3 & 5 & 17 & 25 \\
\hline & $\%$ & $18.8 \%$ & $11.1 \%$ & $25.7 \%$ & $19.7 \%$ \\
\hline \multirow{2}{*}{ hiatal hernia } & No. & 0 & 1 & 1 & 1 \\
\hline & $\%$ & $0.0 \%$ & $2.2 \%$ & $1.5 \%$ & $0.8 \%$ \\
\hline \multirow{2}{*}{ Normal findings } & No. & 3 & 9 & 8 & 20 \\
\hline & $\%$ & $18.8 \%$ & $20.0 \%$ & $12.1 \%$ & $15.7 \%$ \\
\hline \multirow{2}{*}{$\begin{array}{l}\text { Diffuse esophageal } \\
\text { spam }\end{array}$} & No. & 0 & 2 & 2 & 4 \\
\hline & $\%$ & $0.0 \%$ & $4.4 \%$ & $3 \%$ & $3.1 \%$ \\
\hline \multirow{2}{*}{ Total } & 16 & & 45 & 66 & 127 \\
\hline & 100.0 & & $100.0 \%$ & $100.0 \%$ & $100.0 \%$ \\
\hline $\mathrm{X} 2$ & \multicolumn{5}{|c|}{82.98} \\
\hline $\mathrm{P}$ & \multicolumn{5}{|c|}{$0.001 *$} \\
\hline
\end{tabular}

Regarding the duration of dysphagia, in the group of duration more than 24 weeks, the most common findings was malignant esophageal mass in (24\%), followed by GERD in $(22.7 \%)$, then esophageal stricture in $(20 \%)$, normal findings in $(9.3 \%)$, achalasia in $(8 \%)$, combined pathology in $(8 \%)$, and esophageal spasm in $(2.7 \%)$ of the cases. In the group of duration between 12 and 24 weeks, the most common finding was normal finding in $(21.3 \%)$, followed by GERD in (17\%), then esophageal stricture in (14.9\%), achalasia in $(12.8 \%)$, esophageal web/ring in (10.6\%), malignant esophageal mass in $(6.4 \%)$, esinophilic esophagitis in $(4.3 \%)$, other pathology in $(4.3 \%)$, and hiatal hernia in $(4.2 \%)$ of the cases. In the group of duration less than 12 weeks, the most common finding was normal finding (60\%) followed by foreign body impaction in $(40 \%)$ of cases. (Table 4$)$.

Table 4. Endoscopic findings in relation to Duration group.

\begin{tabular}{|c|c|c|c|c|c|}
\hline \multirow{2}{*}{\multicolumn{2}{|c|}{ Endoscopic findings }} & \multicolumn{3}{|c|}{ Duration group } & \multirow{3}{*}{$\begin{array}{l}\text { Total } \\
12\end{array}$} \\
\hline & & \multirow{2}{*}{$\begin{array}{l}<12 \\
0\end{array}$} & \multirow{2}{*}{$\frac{12-24}{6}$} & \multirow{2}{*}{$\begin{array}{l}24+ \\
6\end{array}$} & \\
\hline (1) & No. & & & & \\
\hline Achalasıa & $\%$ & $0.0 \%$ & $12.8 \%$ & $8.0 \%$ & $9.4 \%$ \\
\hline \multirow{2}{*}{ Other findings } & No. & 0 & 2 & 6 & 8 \\
\hline & $\%$ & $0.0 \%$ & $4.3 \%$ & $8.0 \%$ & $6.3 \%$ \\
\hline \multirow{2}{*}{$\begin{array}{l}\text { Eosinophilic } \\
\text { esophagitis }\end{array}$} & No. & 0 & 2 & 4 & 6 \\
\hline & $\%$ & $0.0 \%$ & $4.3 \%$ & $5.3 \%$ & $4.7 \%$ \\
\hline \multirow{2}{*}{ Esophageal ass } & No. & 0 & 3 & 18 & 21 \\
\hline & $\%$ & $0.0 \%$ & $6.4 \%$ & $24.0 \%$ & $16.5 \%$ \\
\hline \multirow{2}{*}{$\begin{array}{l}\text { Esophageal } \\
\text { stricture }\end{array}$} & No. & 0 & 7 & 15 & 22 \\
\hline & $\%$ & $0.0 \%$ & $14.9 \%$ & $20.0 \%$ & $17.3 \%$ \\
\hline \multirow{2}{*}{$\begin{array}{l}\text { Esophageal } \\
\text { web/ring }\end{array}$} & No. & 0 & 5 & 0 & 5 \\
\hline & $\%$ & $0.0 \%$ & $10.6 \%$ & $0.0 \%$ & $3.9 \%$ \\
\hline \multirow{2}{*}{$\begin{array}{l}\text { Foreign body } \\
\text { impaction }\end{array}$} & No. & 2 & 0 & 0 & 2 \\
\hline & $\%$ & $40.0 \%$ & $0.0 \%$ & $0.0 \%$ & $1.6 \%$ \\
\hline \multirow{2}{*}{$\begin{array}{l}\text { GERD/reflux } \\
\text { esophagitis }\end{array}$} & No. & 0 & 8 & 17 & 25 \\
\hline & $\%$ & $0.0 \%$ & $17.0 \%$ & $22.7 \%$ & $19.7 \%$ \\
\hline \multirow{2}{*}{ hiatal hernia } & No. & 0 & 2 & 0 & 2 \\
\hline & $\%$ & $0.0 \%$ & $4.2 \%$ & $0.0 \%$ & $1.6 \%$ \\
\hline \multirow{2}{*}{ Normal findings } & No. & 3 & 10 & 7 & 20 \\
\hline & $\%$ & $60.0 \%$ & $21.3 \%$ & $9.3 \%$ & $15.7 \%$ \\
\hline \multirow{2}{*}{$\begin{array}{l}\text { Diffuse } \\
\text { esophageal spam }\end{array}$} & No. & 0 & 2 & 2 & 4 \\
\hline & $\%$ & $0.0 \%$ & $4.3 \%$ & $2.7 \%$ & $3.1 \%$ \\
\hline \multirow{2}{*}{ Total } & No. & 5 & 47 & 75 & 127 \\
\hline & $\%$ & $100.0 \%$ & $100.0 \%$ & $100.0 \%$ & $100.0 \%$ \\
\hline \multicolumn{2}{|l|}{$\mathrm{X} 2$} & 55.6 & & & \\
\hline \multicolumn{2}{|l|}{$\mathrm{P}$} & $0.001 *$ & & & \\
\hline
\end{tabular}

\section{Discussion}

Dysphagia is a common complain of patients seen in outpatient clinics as well as hospitalized patients [5]. Commonly identified causes of esophageal dysphagia include benign esophageal strictures, malignant esophageal stricture, reflux esophagitis, Schatzki's ring, external compression from a malignancy, motility disorders, scleroderma and achalasia [20]. The prevalence of dysphagia in some population- based studies was up to $17 \%$, with a peak in the $40-49$ years age group for both males and females [5]. It was even more prevalent in the elderly and in the institutionalized patients [8]. Upper GI endoscopy is considered the diagnostic modality of the choice for patients complaining of dysphagia, and it is a 
safe procedure of the initial evaluation of dysphagia [21].

Our study included 127 patients with mean age of $49.56 \pm 16.41$ years. Females comprised $(57.5 \%)$ of the sample while males comprised (42.5\%).In a study by Wilkins et al.[22], also females were affected more than males; $80.8 \%$ women vs $19.2 \%$ men. Majority of our patients 66 (51.9\%) were in the age group above 50 years, indicating that dysphagia is more common in the higher age groups, the same finding was observed by Wilkins et al. [22], stating that the prevalence of dysphagia increases with age and poses particular problems in the elderly subjects potentially compromising the nutritional status, increasing the risk of aspiration pneumonia and adversely affecting the quality of life. Swallowing physiology changes with advancing age, reductions in muscle mass and connective tissue elasticity result in loss of strength, and range of motion [23]. These age-related changes can negatively impact the effective and efficient flow of swallowed materials through the upper digestive tract. Also, normal aging is associated with cerebral atrophy, and deterioration in nerve function, which may adversely affect swallowing function [8,9]. Also age-related decrements in oral moisture, taste, and smell acuity may contribute to reduced swallowing performance in the elderly [24]. Esophageal dysphagia in elderly may result from a number of motor or mechanical causes, and in some patients, no cause can be identified, and categorized as functional dysphagia [25]. In our study, the most common cause of esophageal dysphagia in this group was esophageal masses found in 18 patients $(27.3 \%)$; all were proven to be malignant by histopathological examination and also malignant esophageal stricture which was noted in 5 patients $(22.7 \%)$. Malignant esophageal masses were more common in females $12(16.4 \%)$ than in males 9 (16.7). Also affected patients had dysphagia for more than 24 weeks. This observations indicate that malignant esophageal masses and malignant strictures are important causes of dysphagia in elderly population suffering of dysphagia for more than 24 weeks.

In our study, the most common endoscopic findings was gastro-esophageal reflux disease (GERD)/reflux esophagitis, noted in 25 patients $(19.7 \%)$, with females affected more than males. Majority of patients with GERD/reflux esophagitis; 17 $(25.7 \%)$ were in the age group more than 50 years, followed by 5 patients $(11.1 \%)$ in the age group from $30-50$ years, then 3 patients $(18.8 \%)$ in the age group less than 30 years. 17 patients $(22.7 \%)$ had dysphagia for more than 24 weeks while the reminder 8 patients (17\%) had dysphagia from 12-24 weeks. Thus, GERD/reflux esophagitis are more common in higher age groups, affects females more than males, and associated with long duration of dysphagia. In a study by Satti SA [26], reflux esophagitis, labelled as the most common cause of dysphagia as noted in our study. While, in a study by Krishnamurthy $\mathrm{C}$ et al. [27], esophagitis was the third common cause of dysphagia. Also Khan AN, and his colleagues [28] stated that reflux esophagitis was the third cause of esophageal dysphagia noted in $18.0 \%$ of patients.

The second common finding was esophageal strictures were noted in 22 patients $(17.3 \%)$, affected females were slightly more than males. Esophageal stricture was commoner in the age group from 30-50 years; affected 11 patients (24.4\%), followed by 9 patients $(13.6 \%)$ in the age group more than 50 years, then two patients $(12.5 \%)$ in the age group less than 30 years. 15 patients $(20 \%)$ had dysphagia for more than 24 weeks and 7 patients (14.9\%) had dysphagia from 12-24 weeks. So esophageal strictures are common in middle aged group, affects females more than males, and associated with long duration of dysphagia. Biopsies taken from patients of our study with esophageal stricture revealed 17 patients $(77.3 \%)$ with benign stricture on top of GERD/reflux esophagitis, while 5 patients $(22.7 \%)$ had malignant stricture. Malignant strictures were noted in the patients in the age group more than 50 years, while benign strictures affected middle-age group. Along with our results was Kumbum $\mathrm{K}$ et al. [29], who stated that patients with esophageal strictures had longer duration of reflux symptoms, but on contrary to our results, patient tend to be older, and men were affected more than women. The incidence of malignant strictures was higher in studies by Satti SA et al. [26], and Gillani N et al. [30], found in $22.5 \%$ of the patients in their study. This difference may be due to geographical, dietary or life style implications in the etiology of esophageal or gastric malignancy. On contrary to our results Krishnamurthy et al. [27], found benign oesophageal strictures to be the most common endoscopic abnormality in their study group. It was more common in the age group above 50 years $(66.7 \%)$ and both genders are affected almost equally.

Normal esophageal finding was the third common finding, noted in 20 of our patients $(15.7 \%)$, both males and females are equally affected, it is more common in the age group from $30-50$ years. Most patients, $10(21.3 \%)$ had dysphagia duration from 12-24 weeks. This was comparable with the (20.89\%) frequency observed by Satti SA et al. [26], in their study. In the study conducted by Gillani $\mathrm{N}$ et al. [30], the frequency of normal upper GI endoscopy, however, was $32.5 \%$. The difference may be due to geographic and genetic variation and may be due to difference in the sample size. We found that 9 out of these patients had non-specific, mild esophageal inflammation, while in the rest, biopsies were normal.

Achalasia was the fourth common finding, found in 12 of our patients $(9.4 \%), 7$ patients $(43.8 \%)$ were less than 30 years, 5 patients (11.1\%) in the age group between $30-50$ years while, no patients in the age group more than 50 years. Males affected more than females, half of patients had dysphagia duration from 12-24 weeks and the other half had dysphagia duration for more than 24 weeks. The same findings were observed by Khan AN [28], but the condition was found predominately in patients more than 50 years old. In accordance with our results, Allaix M. stated that achalasia typically occurs in adults aged 25-50 years [31].

Eosinophilic esophagitis was found in 6 patients (4.7\%), with female predominance, affected mainly middle aged patients (30-50 years), most patients had dysphagia for more than 24 weeks. In a study by Moawad FJ and his colleagues [32], the mean age of patients was 26 years, but on contrary to 
our results $72 \%$ of patients were males. Also Veerappan GR. [33], found the prevalence of eosinophilic esophagitis in an outpatient population undergoing upper endoscopy was $6.5 \%$ with male predominance.

Esophageal webs/rings were found in 5(3.9\%) of our patients, with female predominance, affected mainly middle-aged group (30-50 years), and patients had dysphagia duration between 12-24 weeks. Zervos X. [34], stated that esophageal webs are found mostly in female patients. The reason for this gender difference is unknown, but population studies suggest iron deficiency, particularly in menstruating females, may be a cause. In accordance with our results, rings and webs have been identified in all age cohorts. Patients do not typically become symptomatic until after the age of 40 years [34]. Other endoscopic findings were of no statistical significance.

\section{Conclusion}

Based on our results, we concluded that in our population the most common cause of dysphagia is gastro-esophageal reflux disease (GERD) especially in long standing cases, which may progress to Barrett's esophagus and adenocarcinoma of the esophagus. Dysphagia may be associated with serious underlying disorders like carcinoma of the esophagus in majority of elderly patients in our population. Whether this high prevalence of malignancy is due to a recent increase in its occurrence or due to increased recognition remains unclear. We found that the prevalence of malignancy increases in the higher age groups, with slightly female predominance and those having dysphagia for more than 24 weeks duration. Therefore, early upper GI endoscopy should be considered in such cases. Esophageal stricture is another important cause of dysphagia especially in long standing GERD. Upper GI endoscopies were frequently normal in middle-aged and elderly patients suffering of dysphagia for 1-2 years, with no sex difference noted. Achalasia is relatively common in middle-aged females. Other endoscopic findings including; eosinophilic esophagitis, esophageal web/ring, hiatal hernia, foreign body impaction, and diffuse esophageal spam are relatively uncommon causes of dysphagia in our population. Lastly, upper GI endoscopy should be considered in evaluation of dysphagia especially in old age. It is a safe and effective way to evaluate dysphagia and has both diagnostic and therapeutic value.

\section{References}

[1] Brady A. "Managing the patient with dysphagia". Home Healthc Nurse 2008; 26 (1): 41-6; quiz 47-8.

[2] Sleisenger, Marvin H.; Feldman, Mark; Friedman, Lawrence M. Sleisenger \& Fordtran's Gastrointestinal \& Liver Disease 2002; 7th edition. Philadelphia, PA: W.B. Saunders Company. Chapter 6, p. 63.

[3] Logemann, Jeri A. Evaluation and treatment of swallowing disorders. Austin, Tex: Pro-Ed.1998; ISBN 0-89079-728-5.
[4] Locke GR, 3rd, Talley NJ, Fett SL, et al. Prevalence and clinical spectrum of gastroesophageal reflux: a population-based study in Olmsted County, Minnesota. Gastroenterology 1997; 112: 1448-56.

[5] Eslick GD, Talley NJ. Dysphagia: epidemiology, risk factors and impact on quality of life--a population-based study. Aliment Pharmacol Ther 2008;27:971-9.

[6] Martino R, Foley N, Bhogal S, et al. "Dysphagia after stroke: incidence, diagnosis, and pulmonary complications" Stroke 2005; 36 (12): 2756-63.

[7] Mann G, Hankey GJ, Cameron D. Swallowing function after stroke: prognosis and prognostic factors at 6 months. Stroke 1999; 30: 744-8.

[8] Humbert IA, Robbins J. Dysphagia in the elderly. Phys Med Rehabil Clin N Am 2008; 19:853-66.

[9] Shaker R, Staff D. Esophageal disorders in the elderly. Gastroenterol Clin North Am 2001;30(2):335-61.

[10] Longo DL, Fauci AS, Kasper DL,et al. Harrison's Principles of Internal Medicine. 18th ed. New York: McGraw-Hill; 2011. pp. Chapter 38-Dysphagia.

[11] Lew RJ, Kochman ML. A review of endoscopic methods of esophageal dilation. J Clin Gastroenterol 2002; 35:117-26.

[12] Ahtaridis G, Snape WJ, Cohen S. Clinical and manometric findings in benign peptic strictures of the esophagus. Dig Dis Sci 1979 Nov. 24(11):858-61.

[13] Montgomery, EA et al. "Oesophageal Cancer". In Stewart, BW; Wild, CP. World Cancer Report 2014. World Health Organization. pp. 528-43.

[14] De Jonge, PJ; van Blankenstein, M; Grady,et al. "Barrett's oesophagus: epidemiology, cancer risk and implications for management" Gut 2014; 63 (1): 191-202.

[15] Park W, Vaezi M. "Etiology and pathogenesis of achalasia: the current understanding". Am J Gastroenterol 2005; 100 (6): 1404-14.

[16] Chuah, SK; Hsu, PI; Wu, KL; et al. "2011 update on esophageal achalasia." (PDF). World journal of gastroenterology: WJG 18 (14): 1573-8.

[17] Schatzki R, Gary JE. Dysphagia due to a diaphragm-like localized narrowing in the lower esophagus ("lower esophageal ring"). Am J Roentgenol 1953; 70:911-22.

[18] Smout AJ. Advances in esophageal motor disorders. Curr Opin Gastroenterol 2008 Jul. 24(4):485-9.

[19] Blanchard C, Rothenberg ME. "Basic pathogenesis of eosinophilic esophagitis". Gastrointest. Endosc. Clin. N. Am 2008; 18 (1): 133-43.

[20] Palmer KR, Penman ID. Alimentary tract and pancreatic diseases. In: Colledge NR, Walker BR, Ralston SH, editors.Davidson's principles and practice of medicine. 21st edition. Edinburgh: Churchill Livingstone. 2010: p850.

[21] Majeski J, Lynch W, Durst G. Esophageal perforation during esophagogastroduodenoscopy. Am J Surg 2009; 198:56-7.

[22] Wilkins T, Gillies RA, Thomas AM,et al. The prevalence of dysphagia in primary care patients: a Hames Net Research Network study. J Am Board Fam Med.2007; 20:144-50. 
[23] Sura L, Madhavan A, Crary MA. Dysphagia in the elderly: management and nutritional considerations. Clin Interv Aging 2012; 7:287-98.

[24] Fucile S, Wright PM, Chan I, et al. Functional oral-motor skills: Do they change with age? Dysphagia 1998;13:195-201.

[25] Drossman D, editor. Rome III: The Functional Gastrointestinal Disorders. 3rd ed. McLean, VA: Degnon Associates, Inc; 2006.

[26] Satti SA, Ahmed SI, Habib M, et al. Flexible Oesophagoscopy in oesophageal dysphagia: A 134 Patient Series. J Rawal Med Coll 2002;6(1):26-9.

[27] Krishnamurthy C, Hilden K, Peterson KA, et al. Endoscopic findings in patients presenting with dysphagia: analysis of a national endoscopy database. Dysphagia 2012; 27:101-5.

[28] Khan AN, Said Kh, Ahmad M, et al. Endoscopic findings in patients with esophageal dysphagia. J Ayub Med Coll Abbottabad 2014; 26(2):216-20.
[29] Kumbum K, Julian K, Maurice A Cerulli,et al. Esophageal Stricture. Medscape reference. Updated: Dec 16, 2014.

[30] Gilani N, Stipho S, Shaukat MS, et al. The yield and safety of string capsule endoscopy in patients with dysphagia. Gastrointest Endosc. 2007; 66:1091-5.

[31] Allaix ME, Patti MG. Achalasia. Medscape reference. Updated: Nov 06, 2014.

[32] Moawad FJ, Dellon ES, Achem SR,et al. Effects of Race and Sex on Features of Eosinophilic Esophagitis. Clin Gastroenterol Hepatol 2015 Sep 3. pii: S1542-3565(15)01193-3.

[33] Veerappan GR1, Perry JL, Duncan TJ, et al. Prevalence of eosinophilic esophagitis in an adult population undergoing upper endoscopy: a prospective study. Clin Gastroenterol Hepatol. 2009 Apr; 7(4):420-6, 426.e1-2.

[34] Zervos X, Pyrsopoulos. Esophageal Webs and Rings. Medscape reference. Updated: Jul 24, 2015. 